\title{
How Does the Provision of Guided Notes Affect Student Learning in Undergraduate Mathematics?
}

\section{Regula Krapf ${ }^{1}$ (D) . Luca Pfefferkorn ${ }^{2}$}

Accepted: 14 December 2021 / Published online: 10 February 2022

(c) The Author(s) 2022

\begin{abstract}
Note-taking in tertiary education is a challenging activity which requires listening, processing and recording new information at the same time. However, in lectures at a high presentation rate, students often have to choose between these activities. One solution which is frequently proposed to mitigate this problem is the use of guided notes, instructor-provided handouts containing blanks that are filled in class. In this article, we investigate how the provision of guided notes in an undergraduate mathematics course can support student learning. A self-report survey reveals that students value guided notes as a tool to remain focussed during the lecture, to process and store new information and to foster active engagement. Moreover, they prefer guided notes both compared to lectures without instructor-provided notes and with full notes.
\end{abstract}

Keywords Undergraduate mathematics $\cdot$ Note-taking $\cdot$ Guided notes $\cdot$ Tertiary education

\section{Introduction}

Although there have been made many proposals for inquiry-based teaching innovations, the classical lecture still prevails in most undergraduate mathematics classes. The predominant mode of presentation in such lectures is the so-called chalk talk (Artemeva \& Fox, 2011; Greiffenhagen, 2014) in which the instructor writes on a blackboard while the students take notes. One reason why the board presentation remains predominant, is that it allows an authentic illustration of how mathematics is being developed and written. Despite its populartiy among instructors in advanced mathematics, the effectiveness of lectures is often questioned (Leron \& Dubinsky, 1995; Dreyfus, 1991; Davis

Regula Krapf

krapf@math.uni-bonn.de

Luca Pfefferkorn

lpfefferkorn@uni-koblenz.de

1 University of Bonn, Endenicher Allee 60, Bonn D-53115, Germany

2 University of Koblenz-Landau, Universitätsstraße 1, Koblenz 56070, Germany 
\& Hersh, 1981). Although many mathematicians hold complex beliefs about teaching of mathematics and carefully choose their pedagogical moves (Fukawa-Connelly, 2012; Weber, 2004), several studies suggest that the teachers' pedagogical intentions are not always successful (Lew et al., 2016; Fukawa-Connelly et al., 2017). Moreover, according to Yoon et al. (2011) as well as Harris and Pampaka (2016), many students do not expect to learn much from transmissionist style lecturing and they mostly behave passively, i.e. they are reluctant to interact among each other or with the instructor.

One of the main problems associated with mathematics lectures is that the students' attention is usually divided between listening, processing information and note-taking. Frequently, while taking notes, students fall behind and therefore cannot concentrate on the instructor's comments. In some cases, students even copy from the blackboard without understanding what they write (Yoon et al., 2011; Freitag, 2020). Moreover, if the students have to focus too much on note-taking, this could limit their participation in active or interactive learning opportunities such as posing questions. On the other hand, if lecture notes are provided, some students may feel no need to take notes, thus reducing their attentiveness and their active involvement with the material. One potential way to mitigate these problems is to supply the students with guided notes, instructor-generated handouts containing blanks that are filled in class. In this study, we wish to investigate which effects of the provision of guided notes students perceive on their learning inside and outside of mathematics classes.

\section{Literature Review}

\section{General Results on Note-Taking in Higher Education}

While lecturing remains to be the primary instructional method, the vast majority of students take notes while attending lectures and consider this as a useful learning strategy (Armbruster, 2009; Salame \& Thompson, 2020). Numerous studies indicate that note-taking plays a central role for learning and performance in higher education (Salame \& Thompson, 2020; Williams \& Eggert, 2002; Kiewra, 1985b; 1989). For example, Williams and Worth (2002) showed that the note-taking behavior has a higher impact on performance than critical thinking or attendance to lectures, especially if a framework for taking notes is provided.

Two main functions are attributed to note-taking (Di Vesta \& Gray, 1972; 1973): The encoding function or process function states that the act of taking notes itself facilitates learning because it contributes to encoding information, i.e., to interpreting, organizing and storing content (Bligh, 2000), which in turn aids memorization and comprehension. On the other hand, the product function or storage function suggests that notes are helpful for review. Both functions have been shown by extensive research to entail a better learning outcome of note-takers in contrast to nonnote-takers (Kiewra, 1989; Armbruster, 2009; Kobayashi, 2006). Peper and Mayer (1978) discuss several explanations for the effectiveness of the encoding function. Firstly, note-taking is often associated with a higher attentiveness and an increased orientation toward new material. This is particularly valuable, because the students' 
attentiveness tends to decrease as the lecture progresses (Bligh, 2000). Secondly, note-taking requires more effort than mere listening to the instructor's exposition. A third theory proposes that note-takers often need to paraphrase new material and relate it to their prior knowledge, hence assimilating new content. In particular, the studies of Peper and Mayer (1978; 1986) and Einstein et al. (1985) showed notetakers to outperform listeners on transfer problems.

Another interesting finding is that completeness of recorded notes correlates with high test performance if notes are not reviewed Kiewra and Fletcher (1984), indicating that information that is recorded is more likely to be recalled. Nevertheless, Kiewra (1985a) found that the mere process of note-taking affects recall of lecture information less than reviewing the notes. On the other hand, Williams and Eggert (2002) showed that accuracy of notes is an even better predictor of high performance than completeness. However, many students lack note-taking skills (Hughes \& Suritsky, 1994), they often do not capture all the relevant information and ideas presented in lectures (Kiewra, 1985c; Armbruster, 2009; Peverly et al., 2013) and make mistakes (Maddox \& Hoole, 1975). One reason for this is that both the presentation rate and information density tend to be very high in many lectures (Peverly et al., 2013), so that students are required to choose between what they personally see as information worth recording and less significant points. Since the language of mathematics with its conciseness, abstractness and precision (Hertleif, 2016) has a very high information density, this problem applies particularly to mathematics.

One solution to support the storage function and to promote more complete and accurate notes, which is often proposed, is to provide a set of lecture notes for review, because this allows the students to focus more on the lecture and in particular on oral comments. There are mixed results on whether it is more helpful that students study their own notes or instructor-provided full notes (Kiewra, 1989), with some favoring reviewing personal notes e.g., Kiewra and Fletcher (1984) and others favoring provided notes e.g., Maqsud (1980). However, if full notes are provided, students may feel no need to take notes, which can lead to decreased attention and lower the incentive to attend classes (Pardini et al., 2005; Grabe 2005). This is problematic, because attendance to lectures is associated with higher achievement (Credé et al., 2010).

There are several ways to increase effectiveness of note-taking. One possibility consists in cueing, e.g., by writing on the board, because information which is written on the board is more often recorded than oral comments (Kiewra, 1989). In mathematics lectures, where chalk talk is predominant (Greiffenhagen, 2014; Artemeva \& Fox, 2011), this is particularly relevant. Other suggestions include explicitly training students in note-taking (Salame \& Thompson, 2020; Reed et al. 2016) or using guided notes (see below). In this article we pursue the latter approach.

\section{Note-Taking Practices in Undergraduate Mathematics}

Van Meter et al. (1994) found that note-taking practices vary between different academic disciplines. Hence it makes sense to study the particularities of note-taking in mathematics lectures, a field in which only little research has been conducted (Freitag, 2020). 
Freitag (2020) made classroom observations, collected students' notes and conducted interviews with both students and instructors in college mathematics classes. The goals of note-taking that the students reported confirm the general results described in the previous section. The students seemed to be intuitively aware of both the encoding and the storage function, stating that note-taking enabled them to learn the content and that the notes were useful for reference. An interesting finding is that the way the instructor interacted with the board had a great impact on what was recorded, i.e., the students' notes often mirrored the teacher's writings on the board. While some students were more selective in choosing the content they copied, most of them tried to copy everything verbatim from the board, especially if they lacked understanding or prior knowledge. This is problematic, because written proofs in mathematics usually record only the proof product rather than its discovery process (Selden \& Selden, 2014), although instructors often place great significance on their oral comments (Lew et al., 2016). The participants in the study of Lew et al. (2016) often did not manage to grasp the main ideas that the instructor was trying to convey. A follow-up study by Fukawa-Connelly et al. (2017) with a larger sample confirmed these results by showing that only $3.2 \%$ of the spoken comments were recorded by the participants, regardless of the type of content. They further showed that the only informal content that was regularly written on the board were examples, while instructors made comments on informal representations as well as mathematical methods and were modeling mathematical behavior verbally. Freitag (2020) considers difficulties in distinguishing important from less significant content to be a possible explanation for the missing balance between paraphrasing and verbatim copying form the board. Another important factor is the high presentation speed in mathematics (Harris \& Pampaka, 2016), which prevented some students from understanding the mathematics they recorded (Freitag, 2020).

\section{Empirical Results on the Effect of Guided Notes}

As argued in the previous sections, both the encoding and the storage function of note-taking play an essential role for learning outcomes, in particular if they are combined (Kiewra, 1989). This is further supported by Chi (2009) who considers note-taking along with their review not only as an active, but even as a constructive activity. However, against the background of many students' difficulties in paying attention, taking notes, processing and understanding the content at the same time during a lecture at a high presentation rate (Freitag, 2020), the need for a new way of note-taking arises. A promising approach is the provision of guided notes (GN; also called partial notes), which is a set of instructor-prepared lecture notes that contain intentionally inserted blanks which students can fill during the lecture (Heward, 2004). GN are considered as a way of mediating the trade-off in cognitive effort between listenting and note-taking. In order to distinguish GN from lecture notes without blanks, we refer to the latter as full notes $(\mathrm{FN})$.

In the following, we review the main strengths that are ascribed to GN, many of which, however, lack empirical evidence. Although the construction of GN can be time-consuming Chen et al. (2017), once created, GN can be reused without 
further effort (Barbetta \& Scaruppa, 1995). Heward (2004) ascribes several advantages to the use of GN. The selection of text blocks for gaps requires a careful preparation of lectures, thus helping instructors to prioritize and limit lecture content (Heward, 2004). GN also provide an orientation framework for both teachers and students and important aspects can be highlighted better. Being provided with the GN before the lecture, the students can use them as an advance organizer to prepare themselves for the upcoming lecture, e.g., by trying to complete the blanks prior to class (Tonkes et al., 2009). A further key benefit, which was also mentioned in several self-report studies e.g., Narjaikaew et al. (2009); Feudel and Panse (2021), is that GN can have a positive impact on attention and concentration during the lecture. GN can also help students to increase the quality of their notes, by producing complete and accurate notes, which is in turn associated with better performance (see above). Another proposed effect is that the use of GN can increase the active engagement with the lecture content, because by reducing the writing load more time is gained for interaction such as the posing of questions (Austin et al., 2002; Heward, 2004). Cardetti et al. (2010) further postulate that the use of GN increases the incentive to attend lectures. Nevertheless, even supplied with GN, some students still find it difficult to simultaneously take notes and process the lecture (Chen et al., 2017; Barbetta \& Scaruppa, 1995).

Although there are few studies which analyze how the use of GN can support student learning, there are several which investigate the effect on learning achievement. A cross discipline meta-analysis (Larwin \& Larwin, 2013) on the use of guided notes yields a small positive effect on the performance in exams or quizzes relative to instructor-generated full notes and a large impact relative to student-generated notes. A more recent meta-study (Biggers \& Luo, 2020) comes to similar conclusions, stating that the benefits of GN seem to be independent of the subject area. The study of Cornelius and Owen-DeSchryver (2008) further showed that students using GN achieved more than students using full notes in a psychology class on conceptual questions, i.e., questions which required understanding and applying concepts beyond mere memorization. In a more recent study, Chen et al. (2017) investigated whether the use of GN supports the encoding and product functions of note-taking. The authors concluded that filling the blanks does have a positive effect in both ways. However, which variables are responsible for the increased learning outcomes, is still in need of clarification and there are also studies which fail to show a significant impact on performance e.g., Machida et al. (2018); Austin et al. (2004).

In tertiary mathematics, literature on guided notes is still scarce. Most studies suggest that GN enjoy a broad acceptance among students (Montis, 2007; Tonkes et al., 2009; Cardetti et al., 2010; Feudel \& Panse, 2021; Krapf \& Schneider, in press). An analysis of student evaluations (Cardetti et al., 2010) supports the assertion that guided notes increase the students' attention, are useful study aids and help to structure the lecture. In the study of Jaworski and Matthews (2011), an instructor using GN in his classes stated that GN allowed him to "put in quite a lot of commentary about 'this is what we are doing' and 'this is what we are supposed to be thinking about"' (p. 6), hence suggesting that when using GN one can better focus on meta-comments. Two recent studies (Iannone \& Miller, 2019; Feudel \& Panse, 2021) studied university mathematics students' experiences with GN and 
the impact of GN on their note-taking behavior. In both studies, the participants described a reduced pressure to copy from the blackboard, hence paving the way for increased focus on oral explanations and engagement during the lecture. Moreover, in the study of Iannone and Miller (2019), the use GN slightly raised the chance of informal comments being recorded relative to the studies of Lew et al. (2016) and Fukawa-Connelly et al. (2017). Nevertheless, the significance of such comments was still not fully recognized by the students (Iannone \& Miller, 2019). Feudel and Panse (2021) come to a similar conclusion. In their study, students were explicitly asked to compare lectures using GN with traditional chalk talk lectures without handouts. Furthermore, according to them, students gain more understanding during the lecture if GN are provided and therefore need less post-class processing of their notes. Interestingly, while many students described goals of note-taking related to the encoding function, relatively few referred to the product function, e.g., by using GN as a study or homework aid.

\section{Design of the Guided Notes}

In the following, we will describe the way that GN were implemented in our study. The course "Elementary mathematics from a higher standpoint" (ELMA) ${ }^{1}$ in a medium-size German university is a German analogue to a transition to proof course addressed primarily to first semester students who are training to become mathematics teachers at all levels as well as to students of computer science. In the term in question, 342 students were enrolled in the course. It consists of a 90 minutes lecture with a 90 minutes tutorial class and a weekly problem sheet. The course introduces its participants to central concepts of proof-oriented higher mathematics such as logic, set theory, functions and relations with a particular focus on proof methods and problem solving strategies. The lecture was held by the first author. After having held the lecture once with FN, the FN were replaced by GN in the subsequent term. The GN that were used in this study are the result of four cycles of ELMA, in each of which the notes were revised.

When constructing GN, the instructor is confronted with the question which passages to include and which to leave blank. In a survey, Tonkes et al. (2009) noted that students found examples to be particularly suitable for gaps, whereas their opinions were divided on whether definitions should be left blank. However, the course in question was not a proof-oriented lecture, which is why the students were not asked whether to include theorems or proofs. Heward (2004) proposes to include background information and insert blanks for key concepts and relationships. In mathematics this would amount to leaving blanks in statements of definitions and theorems, a path that Smith and Clason (2017) take. A second option is to supply the students with statements of definitions, theorems and examples and working out examples and proofs by filling the gaps (Iannone \& Miller, 2019; Narjaikaew et al., 2009). This has the advantage that the notes constitute a coherent stand-alone text which can principally be read

1 "Elementarmathematik vom höheren Standpunkt" in German 
For propositions $A$ and $B$, the following compound propositions are logically equivalent:

1. $A \Rightarrow B$

2. $\neg A \vee B$

3. $\neg B \Rightarrow \neg A$.

For this reason, it is also possible to define $A \Rightarrow B$ as an abbreviation of $\neg A \vee B$

Proof We compare the truth tables of $A \Rightarrow B, \neg A \vee B$ and $\neg B \Rightarrow \neg A$ :

\begin{tabular}{|cc|ccccc|}
\hline$A$ & $B$ & $A \Rightarrow B$ & $\neg A$ & $\neg A \vee B$ & $\neg B$ & $\neg B \Rightarrow \neg A$ \\
\hline true & true & & & & & \\
true & false & & & & & \\
false & true & & & & & \\
false & false & & & & & \\
\hline
\end{tabular}

Because the truth values of $A \Rightarrow B, \neg A \vee B$ and $\neg B \vee \neg A$ coincide, the three propositions are logically equivalent.

Fig. 1 Extract from the GN used in ELMA in the winter term 2019/20

without knowing the solutions to the blanks (Iannone \& Miller, 2019). Moreover, leaving blanks for process-oriented text blocks such as proofs and examples, implies that automatically more time is spent on these issues. Because the main goal of ELMA is to introduce students to proof-writing, we chose the second approach. More precisely, theorems, definitions, statements of example problems and background knowledge as well as the introduction of new methods such as proof methods were given and solutions to examples, proofs and diagrams had to be filled in.

According to Konrad et al. (2011), one way to improve understanding is to integrate partially completed diagrams. We implemented this in ELMA by e.g. supplying the structure of a truth table (see Fig. 1) or a coordinate system so that the students only had to fill the table or sketch the graph, respectively, without drawing the framework. The idea here is that while drawing a coordinate system does not provide new insights in tertiary mathematics classes, graphing does constitute a pedagogically valuable activity, e.g., when finding examples and non-examples for functions with certain properties, because it can foster the development of adequate concept images.

One goal of the use of GN was to help the students to take responsibility of producing complete and accurate notes (Konrad et al., 2009). Thus, we gradually increased the amount and size of blanks as the semester proceeded. This technique of 'scaffolding and fading' is intended to improve the students' note-taking skills (Reed et al., 2016), because in many other lectures they are required to take their own notes. We implemented this in ELMA by providing proof frameworks such as the steps in induction proofs in the first example presented in class - as illustrated in Fig. 2-, while leaving blanks for the whole proof in later examples.

Because informal comments often fail to be recorded in the students' notes (Lew et al., 2016; Fukawa-Connelly et al., 2017), we took care to include background knowledge such as comments motivating new concepts, heuristic proof ideas, concluding remarks following a proof or hints on potential misconceptions or paradoxes. 
We prove the following equation for each $n \in \mathbb{N}$ by induction:

$$
A(n): \quad \sum_{k=0}^{n} 2^{k}=2^{n+1}-1 .
$$

- Base step:

- Inuction hypothesis (IH): Supoose that $A(n)$, i.e.,

$$
\sum_{k=0}^{n} 2^{k}=2^{n+1}-1
$$

holds for some $n \in \mathbb{N}$.

- Induction step: We have to show $A(n+1)$, i.e., the equation

We have:

Fig. 2 Extract from the GN used in ELMA in the winter term 2019/20

This is exemplified in Fig. 3, where the proof of Euclid's theorem on the infinitude of the set of primes is motivated.

In the ELMA course, the GN were always uploaded at least two days ahead of the lecture, so that students had enough time to print them and to study them in advance. However, because the whole material was covered during the lecture itself, no prior knowledge was explicitly required. In order to refer to definitions and theorems which were completely given in the GN, the instructor used beamer slides containing these sections, i.e., the statements on the slides coincided with the statements which were fully given in the GN. Proofs, examples and diagrams were presented on the board following classical chalk talk. However, while writing the solutions to the blanks on the board, the instructor frequently paused and asked the students to present their ideas to the class of how to complete a proof or an example, so that automatically more time was spent on the sections which contained blanks. The students were further asked to copy the writings on the board in their printed or digital copy of the GN. Although it was often stressed that it is important that the solutions were developped by the participants rather than the instructor, not all students participated equally in the problem solving process; a similar observation concerning passive behavior in undergraduate mathematics classes with a high number of participants was made by Yoon et al. (2011). However, the use of GN was intended to also activate those students who chose not to interact with the instructor by at least filling the gaps and reflecting their writing - as suggested by the following quote from an 
Theorem 1 (Euclid's theorem) There are infinitely many primes.

We briefly recall the definition of a prime number: A natural number $p>1$ is said to be prime, if its only divisors are 1 and $p$.

How can one show the existence of infinitely many objects? Certainly, it is not possible to enumerate all prime numbers explicitly. Instead, we can try to show that the enumeration

$$
2, \quad 3, \quad 5, \quad 7, \quad 13,
$$

of primes never stops. Thus, we aim to show that any finite sequence of primes is incomplete, i.e., if finitely many primes $p_{1}, \ldots, p_{n}$ are given, it is always possible to find another prime which does not occur on the list.

Proof of Theorem 1. [Gap of $8 \mathrm{~cm}$ ]

Fig. 3 Extract from the GN used in ELMA in the winter term 2019/20

instructor: "It allows for the notes to become something that you have but that you ... physically do something with during lecture time" (Jaworski \& Matthews, 2011).

\section{Methods}

Because large-scale studies on the attitudes of students towards the use of guided notes in advanced mathematics are scarce, we seek to answer the following research question:

Which advantages and disadvantages of guided notes do undergraduate mathematics students perceive?

\section{The Survey}

We conducted a survey in the ninth week of the semester in the winter term 2019/20. The participants were informed that the results of the survey would be used for research in mathematics education. Firstly, they were asked to answer the following open-ended question:

What effect do the blanks in the lecture notes have on your learning in your opinion? Please discuss both advantages and disadvantages.

Using four-point Likert scales, the participants were further requested to assess which text segments are suitable for blanks and to rate differents forms of handouts (no notes, FN, GN, beamer slides and guided beamer slides). Finally, they were asked to choose which type of handout they prefer (multiple choices were allowed) and justify their choice in a second open-ended question: 
If you are asked to choose a handout type, which would you choose (Multiple choices allowed)? [No notes/Full notes/Guided notes/Beamer slides/Guided beamer slides]

Please justify your answer.

In this article we focus only on the open-ended questions.

\section{Participants}

The study was conducted as a paper-and-pencil survey in the ninth week of the winter term 2019/20 among the students present in the lecture. Among the 209 participants of our study, 133 were students training to become mathematics teachers (among them 88 in primary education and 45 in secondary education). The remaining 75 students were students of computer science and computational visualistics. Out of the sample, $88 \%$ of the students were freshmen and $50.5 \%$ were female. The computer science students were mostly male $(78.1 \%)$, the gender ratio of the students training to become secondary teachers $(51.1 \%$ male) was balanced, while the students training to become primary teachers were mostly female (77.3\%). The average age of the participants was 20.4 years. With respect to the prior knowledge there are no significant differences between the three groups; all of them have an average high school grade of $2.5^{2}$. Most of the students training to become secondary teachers and the computer science students attended a parallel introductory lecture on linear algebra and analysis, in which the instructor used guided beamer slides that he did, however, not provide in advance but only in the form of completed notes after the lecture. Since such notes cannot be used as a note-taking template during the lecture like GN, they can be considered as full beamer slides. On the other hand, for most of the students training to become primary school teachers ELMA was their only mathematics lecture in the first semester.

\section{Data Analysis}

We used qualitative data analysis according to Mayring (2015) to analyze the answers to the open-ended questions in an iterative cycle of category development and coding. We constructed a category system describing the effects of the use of GN by a combined deductive and inductive approach. In a first step, we created a deductive category system based on the proposed effects of GN we found in literature e.g., Iannone and Miller (2019); Cardetti et al. (2010); Narjaikaew et al. (2009); Biggers and Luo (2020) consisting of code definitions, examples from literature and coding rules. As a preparation for the inductive categorizing, we chose to code meaningful text segments, reaching from

\footnotetext{
2 This corresponds to a grade between $\mathrm{B}$ and $\mathrm{C}^{+}$in the US educational system
} 
single words (e.g., "attention") to multiple sentences. The second author coded the material using the software QDA Miner Lite, either subsuming coding units to an already existing category, inductively creating new catergories or splitting or joining existing categories. Particularly incisive instances were included to replace the deductively chosen examples. Because many passages contained various different effects of the use of GN, we decided to allow multiple coding of the same instance. As recommended by Mayring (2015), the category system was revised systematically by reformulating the category definitions and refining the coding rules once $50 \%$ of the material were coded. Subsequently, the second author proceded to code the whole material using the revised coding scheme. Then the first author coded the material using the same coding manual. Once the material was coded by both coders, we computed the intercoder agreement using Krippendorff's Alpha and obtained the good value of $\alpha=0.842$. Hereby we decided to count two codings as equal, if they overlapped by at least $60 \%$. In the end, disagreements between the two coders were resolved by discussion. Finally, we computed the frequencies of each category.

\section{Findings}

In the following, we summarize the effects that the students reported in the openended questions of our survey. We will differentiate between positive and negative effects. In some cases, effects were reported that could be interpreted both as positive or as negative such as "I MUST take notes." This problem could, however, be resolved because the students usually marked positive effects with a plus symbol "+" and negatively connotated ones with a minus symbol "-". The final coding scheme as well as the deductive coding scheme can be found in the Appendix. Codes starting with "P" refer to positive effects, those starting with "N" to a negative ones. We coded a total number of 877 instances, out of which $615(70.1 \%)$ were positive and $262(29.9 \%)$ were negative.

In the next two sections, respectively, we describe and quantify the positive and negative effects and after that we briefly outline some advantages of FN that students mentioned in their answers to the second open-ended question.

\section{Positive Effects}

Figures 4 and 5 show the quantitative data on the positive effects mentioned by the participants of our study. The codes are ordered as in the presentation of the final coding scheme (see Appendix). More precisely, Fig. 4 shows the percentage of students who mentioned each of the positive effects. However, it does not account for cases when students mentioned the same aspect more than once; this did in fact happen in many cases, as displayed in Fig. 5. 


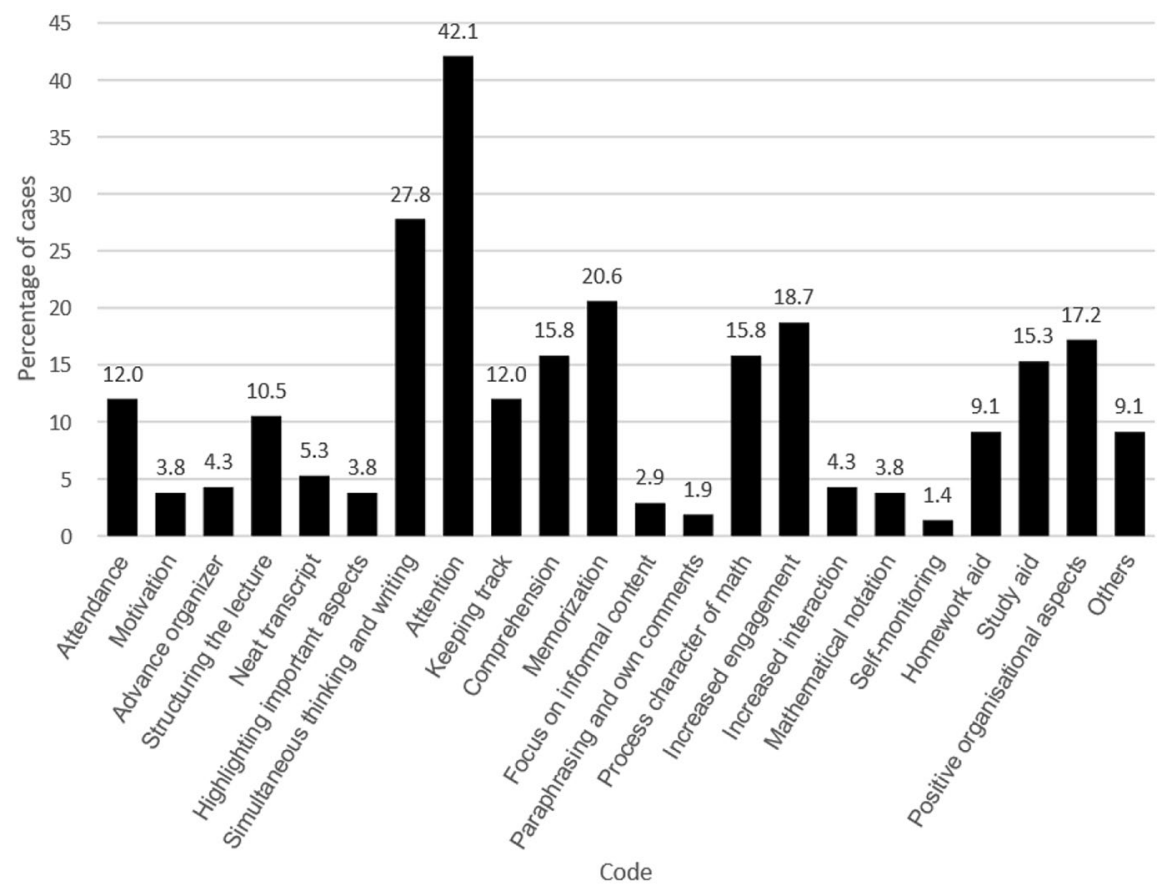

Fig. 4 Quantitative data of the positive effects mentionend by the students: Percentage of cases $(N=209)$

\section{Attendance and Motivation}

Several students reported that the blanks in the GN increased the incentive to attend lectures: "One is more motivated to attend the lecture, because otherwise one would simply study the lecture notes (in the case of full notes without blanks)." In some cases, the students reported a positively connotated pressure rather than incentive to attend: "It forces me to attend the lecture." This is seen by some students as an advantage over the use of FN: "Full notes would tempt me not to attend or not to pay attention." Moreover, while some students pointed out that the use of GN increased their motivation, others emphasized that the blanks made the lecture more varied and hence less monotonous: "The lecture is more varied, because one doesn't just listen regardless". Furthermore, some reported that the blanks increased their willingness to learn: "The gaps ensure thinking along and increase readiness to learn."

\section{Structure and Organization}

A key benefit of GN is that they structure both the lecture and the notes. Firstly, because the GN are provided before the lecture, they can be used as an advance organizer, as the following statement suggests: "It is good that we obtain the notes in advance, because we can already look at them before the lecture." Secondly, the notes provide orientation and function as a thread during the lecture: 


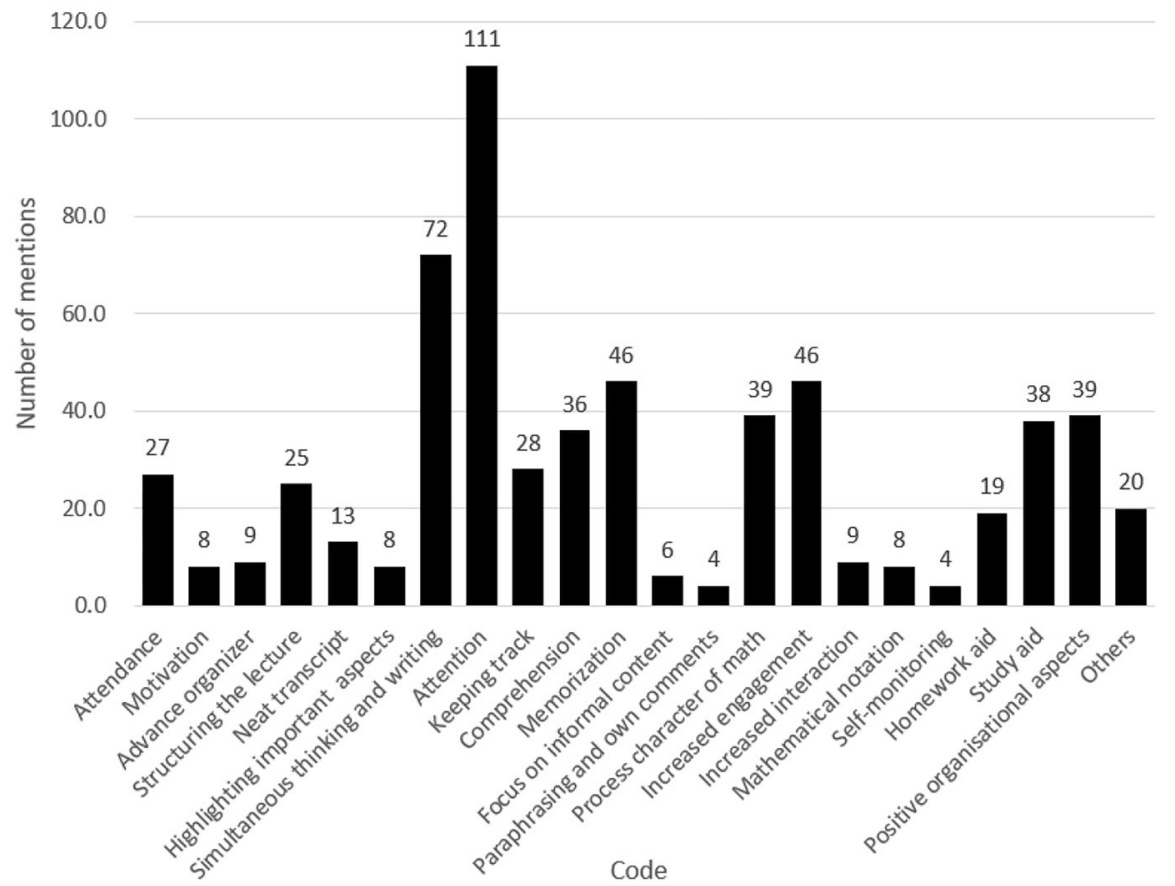

Fig. 5 Quantitative data of the positive effects mentionend by the students: Number of mentions $(N=209)$

"The lecture notes provide a clear-cut guideline, which covers all topics." Thirdly, the design of the GN leads to a transcript which is "neat, because the framework is already given" and accurate. Last but not least, the structure of the GN highlights important aspects: "When I engage with the notes, I can immediately see that I have filled in crucial information myself."

\section{Facilitation of Simultaneous Thinking and Attentiveness}

The students reported that the GN helped them to follow the lecture attentively in several ways. Firstly, they allowed simultaneous thinking, listenting and writing: "One must and can think along. In other mathematical lectures it is impossible to simultaneously take notes and follow, because one has to focus on copying." A second aspect that was frequently mentioned was increased attention and concentration, as exemplified by the following instance: "Personally, I pay much more attention and I am concentrated all the time." Thirdly, by prompting the students to write but relieving them from copying everything, the GN helped the students to follow and keep track of the lecture: "One follows the topic more intensively than if one gets everything written down in advance." These aspects were mentionend particularly often by the participants. 


\section{Encoding and Product Function of Note-Taking}

In accordance with the findings of Freitag (2020), many students seemed to be intuitively aware of both the encoding and the product function of note-taking. They described that note-taking fostered both comprehension and memorization of the lecture content, thus providing further evidence of the encoding function. One student wrote: "The blanks have a positive impact, because I can already understand the topic while I take notes." Another student reported: "One can better remember the blanks, because one has filled them by oneself." This in turn can facilitate reviewing: "It also helps me to study, because when you look at the notes again you remember better what you have done". Moreover, many students valued GN as a helpful aid for review and for solving homework problems, thus underlining the product function of note-taking.

\section{Focus on Informal Content and Own Comments}

According to Iannone and Miller (2019), an important benefit of GN is that they relieve the students from copying everything from the board, hence leaving more time to concentrate on informal verbal comments. However, only few students described such an effect: "One has enough time to follow the explanations during the lecture, because one only has to copy in part instead of everything." Iannone and Miller (2019) further suggest that the use of GN increases the chance of informal comments to be recorded in the students' notes. Although some students did report adding extra comments or paraphrasing, such mentions were quite scarce in our study. One student wrote: "For studying it is nicer, because while taking notes one can also add marginal notes."

\section{Engagement and Interaction}

A further advantage proposed in the note-taking literature is that the provision of GN leads to increased engagement. This was indeed expressed by many students in our study in various ways. Firstly, some described an incentive or even pressure to active engagement, as exemplified by the statements "They [GN] encourage thinking for oneself." and "The blanks help to actively take part in the lecture". Secondly, some students mentioned that filling the gaps together led to increased interaction during the lecture, in particular by asking or answering questions: "By the use of GN and the blackboard one can fill the gaps collectively and ask questions." Thirdly, the students can try to fill in the blanks by themselves and use the writings on the board to check whether their solutions are correct, thus obtaining feedback on their learning status. In this sense, GN foster self-regulated learning. One student even reported using an empty copy of the GN for reviewing the proofs that were presented in the lecture. Moreover, filling the blanks helped to locate difficulties with the lecture content: "It makes it easier to recognize where questions arise." 

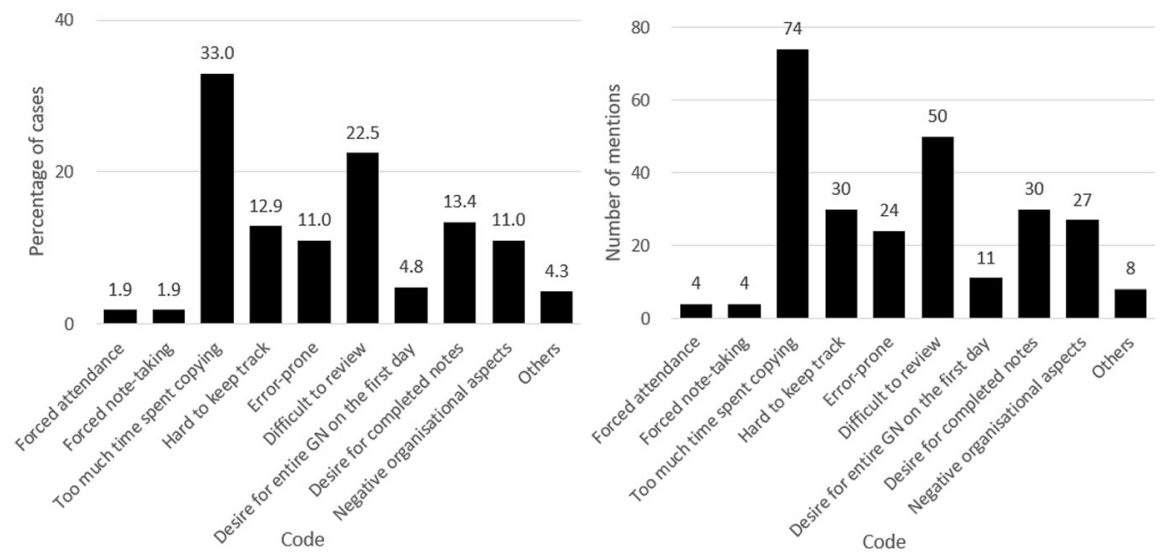

Fig.6 Quantitative data of the negative effects mentionend by the students

\section{Character of Mathematical Practice}

Several students implicitly described that the combined use of GN and the blackboard underlined the process character of mathematics, because the blanks for proofs and examples were filled together step by step, thus demonstrating mathematical problem solving live in an authentic setting. A prototypical citation that was coded in this way is the following: "I find GN very useful, because then one can understand each step bit by bit. This is much more helpful than seeing everything at a glance." In many cases, students explicitly stated that this led to a better understanding and facilitated transfer to homework exercises. One student wrote that "it feels intuitive and helps solving homework problems." In addition, some described that GN helped to practice formal mathematical notation, in particular with respect to proof writing: "Through the act of writing, it is easier to learn how to formulate mathematics correctly and one can better remember and review the examples."

\section{Organizational Aspects}

There were also comments on the combined use of the beamer and the blackboard: "The GN are helpful to follow the lecture, and simultaneously the beamer slides help to keep track of where we are." There were other comments on organisational aspects, e.g. on the size of the blanks. However, while some students considered it ideal, others also critized it (see in the next section).

\section{Negative Effects}

The students also reported several negative effects of GN. The quantitative data on the weaknesses of GN mentioned by the students is illustrated in Fig. 6. Many of 
these coincide with those of note-taking in the absence of instructor-provided notes, in particular with respect to completeness and accuracy of notes and difficulties with simultaneous listening and copying.

\section{Forced Attendance and Note-Taking}

While some students perceived it as beneficial that the use of GN implicitly requires students to attend lectures and take notes, others found this problematic. Thus, one student remarked: "As we don't get a complete version of the notes after the lecture, we are forced to attend, regardless of our medical condition." and another wrote: "We are forced to take notes, because otherwise we don't have the solutions for the blanks." Some students stated that there is no official obligation to attend the lectures and that therefore the blanks were a way of patronizing them and restricting their freedom of choice whether or not to attend.

\section{Heavy Load on Note-Taking}

Another interesting finding is that although many students perceived that GN reduced the load of copying from the blackboard, others commented that even supplied when with GN, too much of their attention was devoted to copying from the blackboard. In particular, many students reported that the presentation speed was too high: "The speed is very high (it is hard to take notes and pay attention)". As a consequence, they could not concentrate on the presented content, which in turn negatively affected their comprehension: "If one is occupied copying from the board during the lecture, one just copies without understanding what one is actually writing." Therefore, some of the participants described that they had trouble following the lecture: "[...] because we simultaneously have to take notes and think along, it is hard to follow."

\section{Incompleteness and Incorrectness of Notes}

Another drawback that several participants reported was that taking notes is prone to errors, as the following citation suggests: "In the case of long/big gaps there is sometimes the uncertainty of having written everything correctly." This, in turn, made reviewing more difficult, particularly if due to illness or other reasons a student cannot attend the lecture: "It causes frustration, if one doesn't have the necessary information, if one couldn't attend the lecture." In addition to that, one student also stated that the blanks restrict the possibility of preparing the lecture in advance.

\section{Organizational Aspects}

Many students expressed the wish to either obtain the whole set of notes at the beginning of the semester instead of updating it week by week or a completed set of notes after each lecture, i.e., with the blanks filled out, as a way to obtain more accurate and complete notes. There are further citations concerning negative organisational aspects, such as the following: "If I don't bring the notes to class, it is hard 
to follow the lecture." Some students also commented on the size and the choice of the blanks, e.g. stating that they were too small.

\section{Advantages of Full Notes}

When asked to choose their preferred handout type, $75.4 \%$ selected GN and $48.3 \%$ selected FN; beamer slides were less popular. In fact, around a forth of the students $(24.0 \%)$ chose a combination of both GN and FN. When asked to justify their answer, several students wrote that GN are helpful during the lecture and FN are useful as a backup to correct mistakes or to complete missing blanks: "Full notes [are helpful] as a backup, in case one cannot keep up or one makes mistakes while taking notes". Those students who chose FN rather than GN as their preferred medium mentioned various advantages of such notes compared to GN, among them that they are more beneficial as a study aid, in particular because note-taking is prone to errors and that blanks are left if students cannot attend the lecture, e.g., due to illness. Moreover, there are several citations stating that complete notes allow to better focus on the lecture, pay attention and understand the presented topics, such as the following: "Simultaneous writing and listening is difficult, hence a reduction of either would be preferable". Other comments suggest that complete notes are better structured, neater than GN and easier to navigate which in turn facilitates reviewing. Two students reported that if FN are provided, there is more time left for adding own comments: "If one cannot take notes (for whatever reason) or if one wants to note additional remarks and does not get everything in the lecture, one has nevertheless complete records for studying and solving homework problems". One student further stated that "[FN are] convenient for studying, because machine-generated text is more readable than handwriting".

\section{Discussion}

\section{Discussion of our Findings}

While research on GN in tertiary educations usually focuses on students' performance, our study provides new insights into the students' viewpoints on the use of GN, a topic that has received little attention with some exceptions (Narjaikaew et al., 2009; Cardetti et al., 2010; Tonkes et al., 2009; Iannone \& Miller, 2019; Feudel \& Panse, 2021). Students were asked to report both strengths and weaknesses of GN. Our findings are generally consistent with previous research. In particular, as in the study of Freitag (2020), our participants showed an intuitive awareness of both the encoding and the product function of note-taking. However, our study includes a larger sample than previous ones and it also documents some new insights such as the impact on attendance or different aspects of structuring provided by GN. Unlike in the study of Feudel and Panse (2021), the participants of our study were not explicitly asked to compare GN with traditional lectures without instructor-prepared handouts but, instead, many students compared GN to 
FN or full beamer slides. Such a preference of GN over FN as our study reveals is indeed remarkable, wheras it seems less surprising that students favour GN over lectures without any form of pre-prepared notes.

The main effect that was reported is that GN help the students to remain attentive and concentrated during the lecture as well as that they allow simultaneous listening and note-taking. This is in line with Peper and Mayer (1978), who link higher attentiveness to the encoding function of note-taking, as well as Cardetti et al. (2010), Narjaikaew et al. (2009) and Feudel and Panse (2021), who consider this as a key benefit of GN. The students frequently described further aspects related to the encoding function, namely that the process of writing facilitates both memorization and comprehension. Freitag (2020) and Yoon et al. (2011) reported that students frequently copied from the board without understanding. Our findings suggest that GN might alleviate this problem to some extent, because many students stated that GN help to keep track of the lecture.

On the other hand, the most cited weakness of GN was that there was still too much time spent copying. Similar observations were made in the studies of Chen et al. (2017) and Barbetta and Scaruppa (1995). In our study, many of the students explicitly used the word "copying", which indicates that as noted by Freitag (2020), students indeed tend to copy verbatim from the board. Interestingly, many students mentioned the same aspect both as a strength and a drawback. This seeming inconsistence could be explained by different points of reference, because the students compared GN both to lectures without instructor-provided notes and to such with FN or complete beamer slides. This explanation is in line with the results of Feudel and Panse (2021), where students made only positive comments on the amount of writing; however, their analysis was based on a comparison to lectures without handout only. This, however, remains to be clarified and is an interesting topic for further research.

Although the students described more effects related to the encoding function of note-taking, unlike in the study of Feudel and Panse (2021) many also underlined that GN were helpful as an aid for both studying and solving homework problems. However, even more students claimed that due to the blanks, GN were difficult to review, because the blanks remained empty in case of illness or when the students failed to keep track, and note-taking is prone to errors. These are problems commonly associated with note-taking in general in the absence of FN Kiewra (1985c); Armbruster (2009); Peverly et al. (2013); Maddox and Hoole (1975) which are not specific to GN. To mitigate this, many students proposed to provide a completed version of the GN after each lecture.

One goal of GN is to increase active engagement by prompting the students to fill out the missing information, while leaving enough time to concentrate on the instructor's comments. Our findings suggest that GN do support active engangement and - at least to some extent - can increase the interactions during the lecture in contrast to classical lectures where interactions are scarce (Yoon et al., 2011). Moreover, the way GN were implemented in our study seems to endorse the advantages of chalk talk (Artemeva \& Fox, 2011; Greiffenhagen, 2014) by conveying a real-time problem-solving process, while still relieving the students from recording everything. This coincides with one of the main aims of the use of GN proposed 
by Tonkes et al. (2009). These authors as well as Iannone and Miller (2019) further expect that having more time left encourages the students to paraphrase new material and add additional comments. Our findings fail to fully support this claim, because only few students reported such an effect. This may, however, also be due to our implementation of the GN which already included such remarks.

Approximately one fifth of the participants ascribed a structuring and organizing effect to GN. According to them, GN can provide structure in several ways, most of which can be found in literature: Firstly, they can be used as an advance organizer ahead of the lectures, secondly, GN function as a guideline during the lecture (Cardetti et al., 2010; Montis, 2007), and thirdly, they also structure the reviewing process by highlighting key concepts and providing a neat and accurate record of the lecture (Cardetti et al., 2010; Narjaikaew et al., 2009). Most of the responses in our study refer to the second aspect, whereas relatively few students used GN as an advance organizer, confirming the findings of Tonkes et al. (2009).

In the study of Tonkes et al. (2009) the students' responses to the question whether they prefer FN rather than GN were neutral. In our study, the corresponding results of the closed questions are somewhat inconclusive: While $90.2 \%$ and $87.6 \%$ of the students rated GN and FN, respectively, as helpful or very helpful in a fourpoint Likert scale, when asked to explicitly choose a form of handout, significantly more students selected GN rather than FN. In fact, one half of those who chose FN actually chose a combination of both GN and FN. It seems that the participants of our study find both GN and FN helpful, but tend to prefer GN when asked to choose. The answers to the open-ended questions suggest that many students favour GN to support learning during the lecture, however wish to have a backup in case they make mistakes while copying or cannot attend class. In fact, many students do not want FN to replace GN, but rather seek to obtain a completed copy after each lecture.

\section{Limitations}

This exploratory study documented self-reported effects of the use of GN in undergraduate mathematics lectures. However, there are also several limitations that we need to address. Firstly, this study did not explore the effect of GN on academic performance. Nevertheless, our results do suggest that GN could have a positive impact on student learning, which is consistent with results from previous studies e.g., Cardetti et al. (2010); Larwin and Larwin (2013); Biggers and Luo (2020). As our findings result from a self-report study, this could be affected by a socialdesirability bias (Krumpal, 2013), as the students might have felt that they were expected to focus on positive aspects.

As the students were explicitly encouraged to describe both adavantages and disadvantages, the proportion of positive and negative effects that were reported may be distorted. In this sense, our study differs from most others which either use only closed questions e.g., Krapf and Schneider (in press); Tonkes et al. (2009) or which did not require students to comment on weaknesses of GN e.g., Cardetti et al. (2010); Iannone and Miller (2019). There are two exceptions to this in the literature: 
Firstly, Narjaikaew et al. (2009) followed a similar approach to ours and prompted their participants to comment both on negative and positive effects in open-ended questions. Unlike our findings, which showed the strengths (615 mentions) to significantly outweigh the weaknesses (262 mentions), their study yielded almost similar numbers of positive and negative views on GN. Secondly, in the study of Feudel and Panse (2021) significantly more positive effects were reported; however, it is important to keep in mind that their participants also attended a traditional lecture without handout.

Because ELMA is usually the first lecture the students enrole in their studies and because most of the students training to become primary school teachers did not visit any other mathematics courses in the same semester, they had little opportunities for comparison within mathematics. Moreover, one can assume that those students compared the teaching method either with their experiences in school or their experiences in other subject areas. This might partially explain the inconsistencies where the same student reported that GN allowed thinking, listening and taking notes simultaneously, while at the same time stating that too much time was spent copying.

It is also unclear whether our findings generalize to other disciplines. Although the literature suggests that the use of GN has a positive impact on learning outcomes independent of the discipline (Larwin \& Larwin, 2013; Biggers \& Luo, 2020), it is also plausible that some reported effects are specific to mathematics, because the way that lecture content is presented is closely reflected in the students' notes (Freitag, 2020) and chalk talk is a phenomenon which is characteristic of mathematics. In particular, the design of GN varies greatly between the disciplines, which is why some effects of GN such as being helpful for learning formal notation might not be generalized to other disciplines.

\section{Implications for Teaching}

Meta-studies on GN indicate that the use of GN has a positive influence on students' learning outcomes (Konrad et al., 2009; Larwin \& Larwin, 2013; Biggers \& Luo, 2020). However, only few studies investigated how the students' learning is affected from their viewpoint. Our study aims to close this research gap. Although students were asked to name both advantages and drawbacks of GN, the positive effects seem to prevail significantly. Hence we may conclude that the provision of GN can support student learning at least to some extent.

Although in the study of Tonkes et al. (2009) the students' responses to the question whether they prefer FN rather than GN are neutral, our results are less clear and suggest that when asked to choose, more students opt for GN. The data also reveals that many students wish GN with an additional completed copy after the lecture, so that they can correct their mistakes. It is thus a difficult balancing act to decide whether or not the instructor should provide a completed version. According to Tonkes et al. (2009), the majority of students claim to take notes 
even if the solutions are provided. This should, however, be empirically tested. If this claim can be substantiated with further evidence, it would indeed be recommendable to provide the completed version afterwards.

One effect of GN which is often neglected in literature is that they create an incentive to attend the lecture, which is viewed positively by $12 \%$ of the participants and further students reported an increased motivation. This confirms the first author's observation that after replacing FN by GN in ELMA, the attendance rate increased. A similar observation was made by Montis (2007). In comparison, only $1.9 \%$ described this as a way of enforcing attendance. In the light of the evidence that attendance is related to higher achievement (Credé et al., 2010), GN can therefore be seen as a low-threshold alternative to compulsory attendance. This is a crucial advantage over FN, because the provision of FN may lower the attendance rate (Pardini et al., 2005; Grabe, 2005).

It is a frequent point of critique that providing GN means spoon-feeding the students by depriving them of the responsibility to organize their notes and to decide what to write. Moreover, GN can give rise to a dependency on the instructor; it is however realistic to assume that not all instructors will adopt this measure. Hence, students need to develop their own note-taking skills. GN can support them, which is why we propose to use GN especially in freshman courses. Nevertheless, in our study still many students noted that even equipped with GN, there is still too much time spent copying. We propose two solutions: Firstly, it makes sense to employ the technique of scaffolding and fading (Reed et al., 2016), by starting with relatively complete notes and increasing the amount of blanks as the semester progresses. In this way, first-year students can gradually acquire note-taking skills which are also required in other lectures and get used to a high presentation speed. Although we already followed this strategy to some extent, this could be employed even more, e.g., by including partially complete proofs or proof frameworks (Selden et al., 2018) - frameworks determined by the logical structure of a proof - rather than having students copy entire proofs. This would extend the idea of using partially completed diagrams as suggested by Konrad et al. (2011) and implemented in ELMA. Secondly, one could explicitly include note-taking training at the beginning, as proposed by Salame and Thompson (2020) or at least instruct the students how to work with GN.

There are different options concerning the question which parts of GN should be left blank. In our case, statements of theorems and definitions were given while proofs and examples as well as, at least partially, diagrams were left blank. The answers to the closed questions indicate that the participants of our study mostly support this choice (e.g., $75.4 \%$ and $84.2 \%$ of the students found proofs and examples, respectively, suitable for gaps). However, the construction of our self-report survey does not allow us to substantiante the claim that these sections are more suitable for gaps than others. Hence, this leaves us with an interesting direction for further research, which could e.g. be investigated by analyzing students' notes, as in the study of Iannone and Miller (2019). 


\section{Conclusions}

In conclusion, while there are many aspects which deserve further exploration, our study supports the claim that GN are a promising learning tool in undergraduate mathematics. In contrast to previous studies, which examined rather small samples of students (Iannone \& Miller (2019) or didn't specifically include open questions to examine the students' perspective on GN (Cardetti et al., 2010), our study represents a large-scale study which does focus on student perception. While this is also true for the study of Feudel and Panse (2021), our study adds the novum that students did not only compare GN to lectures without a handout, but also to lectures using FN. Apart from providing further evidence for the positive effect of GN on aspects such as attention and understanding, which was found in previous small-scale as well as large-scale studies, our study implies that GN may serve as a valuable study aid after the lecture, an advantage suggested by Cardetti et al. (2010), but not confirmed in the large-scale study by Feudel and Panse (2021). Next to these effects, which have already gained support across various studies, our study suggests that GN may have the potential to raise students' awareness of the character of mathematical practice, to structure both the lecture and the notes in various ways, and to motivate students to attend the lecture.

\section{Appendices}

Initial deductive coding list

1. GN increase the incentive to attend lectures (Cardetti et al., 2010; Krapf, in press; Krapf \& Schneider, in press; Babb \& Ross, 2009)

2. GN can be used as an advance organizer (Babb \& Ross, 2009; Tonkes et al., 2009)

3. GN serve as a structural guidance (Decker, 2017; Cardetti et al., 2010; Montis, 2007; Smith \& Clason, 2017)

4. GN lead to neat transcripts (Montis, 2007; Cardetti et al., 2010)

5. GN highlight important aspects (Cardetti et al., 2010; Narjaikaew et al., 2009; Heward, 2004; Reed et al., 2016)

6. GN enable students to write and think simultaneously (Cardetti et al., 2010; Panse, 2018; Montis, 2007; Iannone \& Miller, 2019; Narjaikaew et al., 2009)

7. GN lead to increased attention and concentration (Panse, 2018; Narjaikaew et al., 2009; Krapf, in press)

8. GN make it easier for the students to follow the lecture (Panse, 2018; Decker, 2017, 2018; Cardetti et al., 2010; Montis, 2007)

9. Filling the gaps of GN helps students to better understand and remember the lecture content (process function of writing) (Smith \& Clason, 2017; Krapf, in press; Cardetti et al., 2010; Chen et al., 2017; Tonkes et al., 2009)

10. GN leave more time to focus on informal verbal comments (Iannone \& Miller, 2019; Montis, 2007; Austin et al., 2004) 
11. GN offer the possibility to paraphrase information and add extra comments (Cardetti et al., 2010; Panse \& Feudel, 2019; Austin et al., 2004)

12. GN increase activity in lectures (Cardetti et al., 2010; Iannone \& Miller, 2019; Krapf, in press; Narjaikaew et al., 2009; Tonkes et al., 2009; Alcock, 2018)

13. GN lead to increased interaction during lectures (Panse, 2018; Montis, 2007; Heward, 2004; Alcock, 2018)

14. GN are a useful study aid for review (Decker, 2017; Cardetti et al., 2010; Iannone \& Miller, 2019; Montis, 2007; Chen et al., 2017)

15. GN still involve a considerable amount of writing which makes simultaneous thinking and following of the lecture difficult (Krapf, in press)

16. GN are more prone to incompleteness and errors than FN (Kiewra, 1985b; Kiewra et al., 2018)

Final coding scheme

\begin{tabular}{lll}
\hline Category1 & Description & Example \\
\hline P1: Attendance & $\begin{array}{c}\text { GN increase the incentive to } \\
\text { attend lectures. }\end{array}$ & $\begin{array}{c}\text { "One is more motivated to attend } \\
\text { the lecture, since otherwise one } \\
\text { would simply study the lecture } \\
\text { notes (in the case of full notes } \\
\text { without blanks)." } \\
\text { "It forces me to attend the lec- } \\
\text { ture." }\end{array}$ \\
\end{tabular}

P2: Motivation

P3: Structure and guidance

P3.1: Advance Organizer

P3.2: Structuring the lecture

P3.3: Neat transcript

P3.4: Highlighting important aspects

P4: Facilitating simultaneous thinking and attentive listening

P4.1: Simultaneous thinking and writing
GN make lectures more motivating and less monotonous.

"GN lead to increased motivation"

"The lecture is more varied, since one doesn't just listen regardless."

GN offer an overview of the coming lecture and can serve as an advance organizer.

GN provide a structural framework which functions as a guideline during the lecture.

GN offer a structural framework which leads to a neat transcript.

The structure of GN highlights important aspects.

GN allow simultaneous thinking, listening and writing.
"It is good that we obtain the notes in advance, because we can already look at them before the lecture."

"The lecture notes provide a clearcut guideline, which covers all topics."

"Neat, since the framework is already given."

"Shows which parts are of special importance"

"When I engage with the notes, I can immediately see that I have filled in crucial information myself."

"One must and can think along. In other mathematical lectures it is impossible to simultaneously take notes and follow, since one has to focus on copying." 


\begin{tabular}{ll}
\hline Category1 & Description \\
\hline P4.2: Attention & $\begin{array}{c}\text { GN lead to increased attention } \\
\text { andconcentration. }\end{array}$ \\
P4.3: Keeping track & $\begin{array}{l}\text { Prompting students to write but } \\
\text { relieving them of copying } \\
\text { everything, GN help them } \\
\text { to follow and keep track of the } \\
\text { lecture. }\end{array}$
\end{tabular}

Example

P5: Process function of notetaking

P5.1: Comprehension

The process of gap filling facilitates comprehension of lecture content.

\section{P5.2: Memorization}

Lecture content which has to be written in gaps is more memorable to students.

"Personally, I pay much more attention and I am concentrated all the time."

"One follows the topic more intensively than if one gets everything written down in advance."

P6: Focus on informal content

Relieving students of copying everything from the board, GN allow them more time to focus on informal verbal comments.

P7: Paraphrasing and own comments

The gaps and the reduced amount of writing offer students the opportunity to paraphrase explanations and to add own comments.

P8: Process character of mathematics

P9: Increased engagement

The act of filling the gaps step by step underlines the process character of mathematics and helps students understand examples and proofs.

GN lead to increased engagement during the lecture.

P10: Increased interaction

P11: Mathematical notation

The act of filling the gaps together leads to increased interaction during the lecture, especially by triggering students to ask or answer questions.

The act of gap filling sensitizes students to the formal mathematical notation, in particular to the correct formulation of proofs.

"The blanks have a positive impact, since I can already understand the topic while I take notes."

"One can better remember the blanks, because one has filled them by oneself."

"One has enough time to follow the explanations during the lecture, since one only has to copy in part instead of everything."

"For studying it is nicer, since while taking notes one can also add marginal notes."

"This way, you also get the opportunity to write down the verbal comments."

"I find GN very useful, since then one can understand each step bit by bit. This is much more helpful than seeing everything at a glance."

"The blanks help to actively take part in the lecture."

"They [GN] encourage thinking for oneself."

"By the use of GN and the blackboard one can fill the gaps collectively and ask questions."

"Through the act of writing it is easier to learn how to formulate mathematics correctly and one can better remember and review the examples."

"Already practice in writing down proofs" 


\begin{tabular}{l} 
Category1 \\
\hline P12: Self-monitoring \\
P13: Product function of note- \\
taking
\end{tabular}

P13.1: Homework aid

P13.2: Study aid

P14: Positive organisational aspects

P15: Other positive aspects

N1: Forced attendance

N2: Forced note-taking

N3: Too much time spent copying

\section{N4: Hard to keep track}

N5: Error-prone
Description

While filling the gaps, students reflect on the lecture content and thus get feedback on their current learning status and become aware of potential difficulties.

GN represent a useful tool providing guidance when solving homework problems.

GN serve as a helpful study aid for review and exam preparation.

Organisational matters such as the specific design of GN and their combined use with slides are highlighted as positive aspects.

GN and the lecture in general are described as positive without expressing any specific effect.

The gaps in GN implicitly force students to attend the lecture and thus contradict its voluntary nature.

The provision of GN forces students to fill the blanks and patronizes them in terms of note-taking format.

Working with GN, students still have to spend too much time on copying which impedes simultaneous listening and thinking.

While filling the gaps, students have difficulties to follow the lecture and thus lose track of the instructor.

The fact that students have to fill gaps in the lecture notes makes GN prone to errors.
Example

"Self-monitoring while filling the gaps"

"It makes it easier to recognize where questions arise."

"While doing homework exercises, you can use them [GN] as a guideline."

"Look up examples and apply them to homework exercises"

"They [GN] really help to review lecture content and are also useful for exam preparation."

"Organisational matters such as the specific design of GN and their combined use with slides are highlighted as positive aspects."

"The gaps are very good. Not too big/small."

"GN are great."

"[...] is this form of notes the best for me."

"Since we don't get a complete version of the notes after the lecture, we are forced to attend, regardless of our medical condition."

"We are forced to take notes, since otherwise we don't have the solutions for the blanks."

"If one is occupied copying from the board during the lecture, one just copies without understanding what one is actually writing."

"The speed is very high (it is hard to take notes and pay attention)."

"[...] since we simultaneously have to take notes and think along, it is hard to follow."

"In the case of long/big gaps there is sometimes the uncertainty of having written everything correctly." 


\begin{tabular}{|c|c|c|}
\hline Category 1 & Description & Example \\
\hline N6: Difficult to review & $\begin{array}{l}\text { In case of absence during } \\
\text { lectures orerroneously and } \\
\text { incompletely filled gaps, GN } \\
\text { are difficult to review. }\end{array}$ & $\begin{array}{l}\text { "Difficult to review if you have } \\
\text { missed a piece of information } \\
\text { and the gap remainsempty." } \\
\text { "It causes frustration, if one } \\
\text { doesn't have the necessary infor- } \\
\text { mation, if one couldn't attend } \\
\text { the lecture." }\end{array}$ \\
\hline $\begin{array}{l}\text { N7: Desire for entireGN on the } \\
\text { first day }\end{array}$ & $\begin{array}{l}\text { Students express the wish to } \\
\text { obtain the whole set of GN at } \\
\text { the beginning of the semester } \\
\text { instead of weekly updates. }\end{array}$ & $\begin{array}{l}\text { "It would be better to upload the } \\
\text { whole set of lecture notes at } \\
\text { the beginning to avoidweekly } \\
\text { downloads." }\end{array}$ \\
\hline N8: Desire forcompleted notes & $\begin{array}{l}\text { Students wish for a completed } \\
\text { set of notes after each lecture, } \\
\text { i.e., with the blanks filled out, } \\
\text { as a way to obtain more accu- } \\
\text { rate and complete notes. }\end{array}$ & $\begin{array}{l}\text { "GN during the lecture, but a } \\
\text { completed set of notes for } \\
\text { review" }\end{array}$ \\
\hline $\begin{array}{l}\text { N9: Negativeorganisational } \\
\text { aspects }\end{array}$ & $\begin{array}{l}\text { Organisational matters such } \\
\text { as the specific design of GN } \\
\text { and their combined use with } \\
\text { slides are marked as negative } \\
\text { aspects. }\end{array}$ & $\begin{array}{l}\text { "Combination with slides } \\
\text { impractical, as there are multiple } \\
\text { sources to review" } \\
\text { "Sometimes, the gaps are too } \\
\text { small." }\end{array}$ \\
\hline N10: Other negativeaspects & $\begin{array}{l}\text { GN and the lecture in general are } \\
\text { described as negative without } \\
\text { expressing any specific effect. }\end{array}$ & $\begin{array}{l}\text { "Gaps in the lecture notes don't } \\
\text { help." }\end{array}$ \\
\hline
\end{tabular}

Funding Open Access funding enabled and organized by Projekt DEAL.

\section{Declarations}

Conflict of Interest On behalf of both authors, the corresponding author states that there is no conflict of interest.

Open Access This article is licensed under a Creative Commons Attribution 4.0 International License, which permits use, sharing, adaptation, distribution and reproduction in any medium or format, as long as you give appropriate credit to the original author(s) and the source, provide a link to the Creative Commons licence, and indicate if changes were made. The images or other third party material in this article are included in the article's Creative Commons licence, unless indicated otherwise in a credit line to the material. If material is not included in the article's Creative Commons licence and your intended use is not permitted by statutory regulation or exceeds the permitted use, you will need to obtain permission directly from the copyright holder. To view a copy of this licence, visit http://creativecommons.org/licenses/ by $/ 4.0 \%$.

\section{References}

Alcock, L. (2018). Tilting the classroom. London Mathematical Society Newsletter, 474, 22-27.

Armbruster, B. B. (2009). Notetaking from lectures. In R. F. Flippo \& D. C. Caverly (Eds.), Handbook of college reading and study strategy research (pp. 220-248). New York: Lawrence Erlbaum. 
Artemeva, N., \& Fox, J. (2011). The writings on the board: The global and local in teaching undergraduate mathematics through chalk talk. Written Communication, 28(4), 345-379.

Austin, J. L., Lee, M. G., \& Carr, J. E. (2004). The effects of guided notes on undergraduate students' recording of lecture content. Journal of Instructional Psychology, 31(4), 314-320.

Austin, J. L., Lee, M. G., Thibeault, M. D., Carr, J. E., \& Bailey, J. S. (2002). Effects of guided notes on university students' responding and recall of information. Journal of Behavioral Education, 11(4), 243-254.

Babb, K., \& Ross, C. (2009). The timing of online lecture slide-availability and its effect on attendance, participation, and exam performance. Computers \& Education, 52(4), 868-881.

Barbetta, P. M., \& Scaruppa, C. L. (1995). Looking for a way to improve your behavior analysis lectures? Try guided notes. The Behavior Analyst, 18(1), 155-160.

Biggers, B., \& Luo, T. (2020). Guiding students to success: A systematic review on research on guided notes as an instructional strategy from 2009-2019. Journal of University Teaching \& Learning Practice, 17(3), 1-12.

Bligh, D. (2000). What's the use of lectures? New York: Wiley.

Cardetti, F., Khamsemanan, N., \& Orgnero, M. C. (2010). Insights regarding the usefulness of partial notes in mathematics courses. Journal of the Scholarship of Teaching and Learning, 10(1), 80-92.

Chen, P. H., Teo, T., \& Zhou, M. (2017). Effects of guided notes on enhancing college students' lecture note-taking quality and learning performance. Current Psychology, 36(4), 719-732.

Chi, M. (2009). Active - constructive - interactive: A conceptual framework for differentiating learning activities. Topics in Cognitive Science, 1(1), 73-105.

Cornelius, T. L., \& Owen-DeSchryver, J. (2008). Differential effects of full and partial notes on learning outcomes and attendance. Teaching of Psychology, 35(1), 6-12.

Credé, M., Roch, S. G., \& Kieszcszynka, U. M. (2010). Class attendance in college: A meta-analytic review of the relationship of class attendance with grades and student characteristics. Review of Educational Research, 80(2), 272-295.

Davis, P. J., \& Hersh, R. (1981). The mathematical experience. Boston: Birkhäuser.

Decker, E. (2017). Tablet-basiertes Mitmach-Skript. In: Zentrum für Hochschuldidaktik (ed) Tagungsband zum 3. HDMINT Symposium zur Hochschullehre in den MINT-Fächern 2017, (pp 168-173). DiNa-Sonderausgabe, Technische Hochschule Nürnberg, Nürnberg, Germany.

Decker, E. (2018). Vorlesung per Tablet. Chance zur Förderung von Aktivierung und strukturierter Ergebnissicherung bei Studienanfängern. In: Fachgruppe Didaktik der Mathematik der Universität Paderborn (ed) Beiträge zum Mathematikunterricht 2018, (pp 433-436),WTM, Münster, Germany.

Di Vesta, F. J., \& Gray, S. G. (1972). Listening and note-taking. Journal of Educational Psychology, 61(1), 8-14.

Di Vesta, F. J., \& Gray, S. G. (1973). Listening and note-taking ii. Immediate and delayed recalls as functions of variations in thematic continuity, note-taking, and length of listening-review intervals. Journal of Educational Psychology, 64(3), 278-287.

Dreyfus, T. (1991). Advanced mathematical thinking processes. In D. Tall (Ed.), Advanced Mathematical Thinking (pp. 25-41). Dordrecht: Kluwer.

Einstein, G. O., Morris, J., \& Smith, S. (1985). Note-taking, individual differences, and memory for lecture information. Journal of Educational Psychology, 77(5), 522-532.

Feudel, F., \& Panse, A. (2021). Can guided notes support students' note-taking in mathematics lectures? International Journal of Research in Undergraduate Mathematics Education. https://doi.org/10. 1007/s40753-021-00146-9.

Freitag, M. A. (2020). Note-taking practices of students in college mathematics. International Journal of Research in Undergraduate Mathematics Education, 6(1), 65-89.

Fukawa-Connelly, T. (2012). A case study of one instructor's lecture-based teaching of proof in abstract algebra: Making sense of her pedagogical moves. Educational Studies in Mathematics, 81(3), 325-345.

Fukawa-Connelly, T., Weber, K., \& Mejía-Ramos, J. P. (2017). Informal content and student note-taking in advanced mathematics classes. Journal for Research in Mathematics Education, 48(5), 567-579.

Grabe, M. (2005). Voluntary use of online lecture notes: Correlates of note use and note use as an alternative to class attendance. Computers \& Education, 44(4), 409-421.

Greiffenhagen, C. (2014). The materiality of mathematics: Presenting mathematics at the blackboard. The British Journal of Sociology, 65(3), 502-528.

Harris, D., \& Pampaka, M. (2016). 'They [the lecturers] have to get through a certain amount in an hour': First year students' problems with service mathematical lectures. Teaching Mathematics and Its Applications, 35(3), 144-158. 
Hertleif, C. (2016). "Und wie soll ich das jetzt aufschreiben?". Über gutes Aufschreiben, Einstellungen im Schreibprozess und Schreibförderung. In: Paravicini W, Schnieder J (eds) Hanse-Kolloquium zur Hochschuldidaktik der Mathematik 2014, (pp 63-76), WTM, Münster, Germany.

Heward, W. L. (2004). Want to improve the effectiveness of your lectures? Try guided notes. Talking about Teaching, 1, 33-46.

Hughes, C. A., \& Suritsky, S. K. (1994). Note-taking skills of university students with and without learning disabilities. Journal of Learning Disabilities, 27(1), 20-24.

Iannone, P., \& Miller, D. (2019). Guided notes for university mathematics and their impact on students' note-taking behaviour. Educational Studies in Mathematics, 101(3), 387-40.

Jaworski, B., \& Matthews, J. (2011). How we teach mathematics: Discourses on/in university teaching. In M. Pytlak, T. Rowland, \& E. Swoboda (Eds.), Proceedings of the Seventh Congress of the European Mathematical Society for Research in Mathematics Education (pp. 2022-2032). Rzeszów, Poland: University of Rzeszów and ERME.

Kiewra, K. A. (1985a). Examination of the encoding and external-storage functions of notetaking for factual and higher-order performance. College Student Journal, 19(4), 394-397.

Kiewra, K. A. (1985b). Providing the instructor's notes: Aan effective addition to student notetaking. Educational Psychologist, 20(1), 33-39.

Kiewra, K. A. (1985c). Students' note-taking behaviors and the efficacy of providing the instructor's notes for review. Contemporary Educational Psychology, 10(4), 378-386.

Kiewra, K. A. (1989). A review on note-taking: The encoding-storage paradigm and beyond. Educational Psychology Review, 1(2), 147-172.

Kiewra, K. A., Colliot, T., \& Lu, J. (2018). Note this: How to improve student note taking. IDEA Paper \#73.

Kiewra, K. A., \& Fletcher, J. J. (1984). The relationship between levels of notetaking and achievement. Human Learning, 3(4), 273-280.

Kobayashi, K. (2006). Combined effects of note-taking/-reviewing on learning and the enhancement through interventions: A meta-analytic review. Educational Psychology, 26(3), 459-477.

Konrad, M., Joseph, L. M., \& Eveleigh, E. (2009). A meta-analytic review of guided notes. Education and Treatment of Children, 32(3), 421-444.

Konrad, M., Joseph, L. M., \& Itoi, M. (2011). Using guided notes to enhance instruction for all students. Intervention in School and Clinic, 46(3), 131-140.

Krapf, R. (in press). Wie kann Interaktivität in Mathematikvorlesungen gelingen? Erfahrungen aus dem Koblenzer Vorkurs. Preprint.

Krapf, R., \& Schneider, F. (in press). Konzeption und Wirkung eines Vorkurses zur Einführung in die Hochschulmathematik unter Einbezug aktivierender Lehrmethoden. Preprint.

Krumpal, I. (2013). Determinants of social desirability bias in sensitive surveys: A literature review. Quality \& Quantity, 47(4), 2025-2047.

Larwin, K. H., \& Larwin, D. A. (2013). The impact of guided notes on postsecondary student achievemnt: A meta-analysis. International Journal of Teaching and Learning in Higher Education, 25(1), 47-58.

Leron, U., \& Dubinsky, E. (1995). An abstract algebra story. American Mathematical Monthly, 102(3), 227-24.

Lew, K., Fukawa-Connelly, T. P., Mejía-Ramos, J. P., \& Weber, K. (2016). Lectures in advanced mathematics: Why students might not understand what the mathematics professor is trying to convey. Journal for Research in Mathematics Eduation, 47(2), 162-198.

Machida, K., Chin, M., \& Johnson, K. A. (2018). The provision of partial notes is not associated with improved student attention in lectures or subsequent understanding of the lecture material. Active Learning in Higher Education, 19(2), 101-115.

Maddox, H., \& Hoole, E. (1975). Performance decrement in the lecture. Educational Review, 28(1), 17-30.

Maqsud, M. (1980). Effects of personal lecture notes and teacher-notes on recall of university students. British Journal of Educational Psychology, 50(3), 289-294.

Mayring, P. (2015). Qualitative Inhaltsanalyse. Grundlagen und Techniken, 3rd edn. Beltz, Weinheim, Germany.

Montis, K. K. (2007). Guided notes: An interactive method for success in secondary and college mathematics classrooms. Focus on Learning Problems in Mathematics, 29(3), 55-68. 
Narjaikaew, P., Emarat, N., \& Cowie, B. (2009). The effect of guided note-taking during lectures on thai university students' understanding of electromagnetism. Research in Science Technological Education, 27(1), 75-94.

Panse, A. (2018). Lehrinnovationen mit angehenden Gymnasiallehrern. In: Fachgruppe Didaktik der Mathematik der Universität Paderborn (ed) Beiträge zum Mathematikunterricht 2018, (pp 13711374), WTM, Münster, Germany.

Panse, A., \& Feudel, F. (2019). "Auf einmal kann ich auch mitdenken" - Mitschreiben in Vorlesungen mit Lückenskript. In A. Frank, S. Krauss, \& K. Binder (Eds.), Beiträge zum Mathematikunterricht 2019 (pp. 605-608). Germany: WTM, Münster.

Pardini, E. A., DA Domizi, Forbes, \& Pettis, G. V. (2005). Parallel note-taking: A strategy for effective use of webnotes. Journal of College Reading and Learning, 35(2), 38-55.

Peper, R. J., \& Mayer, R. E. (1978). Note-taking as a generative activity. Journal of Educational Psychology, 70(4), 514-522.

Peper, R. J., \& Mayer, R. E. (1986). Generative eects of note-taking during science lectures. Journal of Educational Psychology, 78(1), 34-38.

Peverly, S. T., Vekaria, P. C., Reddington, L. A., Sumowski, J. F., Johnson, K. R., \& Ramsay, C. M. (2013). The relationship of handwriting speed, working memory, language comprehension and outlines to lecture note-taking and test-taking among college students. Applied Cognitive Psychology, 27(1), 115-126.

Reed, K. D., Rimel, H., \& Hallett, A. (2016). Note-taking interventions for college students: A synthesis and meta-analysis of the literature. Journal of Research on Educational Effectiveness, 9(3), 307-333.

Salame, I. I., \& Thompson, A. (2020). Students' views on strategic note-taking and its impact on performance, achievement, and learning. International Journal of Instruction, 13(2), 1-16.

Selden, A., \& Selden, J. (2014). The genre of proof. In M. N. Fried \& T. Dreyfus (Eds.), Mathematics \& Mathematics Education: Searching for Common Ground (pp. 248-251). Dordrecht: Springer.

Selden, A., Selden, J., \& Benkhalti, A. (2018). Proof frameworks: A way to get started. Problems, Resources, and Issues in Mathematics Undergraduate Studies, 20(1), 31-45.

Smith, K., \& Clason, D. (2017). Using blanks in guided lecture notes. AURCO Journal, 23, 103-115.

Tonkes, E. J., Isaac, P. S., \& Scharaschkin, V. (2009). Assessment of an innovative system of lecture notes in first-year mathematics. International Journal of Mathematical Education in Science and Technology, 40(4), 305-320.

Van Meter, P., Yokoi, L., \& Pressley, M. (1994). College students' theory of note-taking derived from their perceptions of note-taking. Journal of Educational Psychology, 86(3), 323-338.

Weber, K. (2004). Traditional instruction in advanced mathematics courses: A case study of one professor's lectures and proofs in an introductory real analysis course. Journal of Mathematical Behavior, 23(2), 115-133.

Williams, R. L., \& Eggert, A. C. (2002). Notetaking in college classes: Student patterns and instructional strategies. The Journal of General Education, 51(3), 173-199.

Williams, R. L., \& Worth, S. L. (2002). Thinking skills and working habits: Contributors to course performance. The Journal of General Education, 51(3), 200-277.

Yoon, C., Kensington-Miller, B., Sneddon, J., \& Bartholomew, H. (2011). It's not the done thing: Social norms governing student's passive behaviour in undergraduate mathematics lectures. International Journal of Mathematical Education in Science and Technology, 42(8), 1107-1122.

Publisher's Note Springer Nature remains neutral with regard to jurisdictional claims in published maps and institutional affiliations. 